\title{
Recurrent swellings of the parotid gland
}

\author{
R. S. BRUCE PEARSON \\ From King's College Hospital, London
}

SYNOPSIS This paper presents an analysis of 104 (43 men and 61 women) patients who had been investigated for recurrent swelling of the parotid gland. The investigation and causes of this condition are discussed.

Initially all patients had recurrent swellings which subsided completely between attacks, but in some, particularly in those with Sjögren's syndrome, the swellings ultimately became persistent. Table I shows distribution of cases in 10-year periods according to age and sex.

\section{TABLE I}

\begin{tabular}{lrrrrrrr}
\multicolumn{7}{c}{ AGE AND SEX } \\
& $\begin{array}{l}\text { Age in } \\
0-9\end{array}$ & 10 Years & & & & & \\
& & & $20-29$ & $30-39$ & $40-49$ & $50-59$ & $60+$ \\
\hline Male & 18 & 10 & 4 & 2 & 3 & 4 & 2 \\
Female & 8 & 4 & 5 & 12 & 8 & 14 & 10 \\
Total & 26 & 14 & 9 & 14 & 11 & 18 & 12
\end{tabular}

It will be seen that the largest group of cases occurs in the first two decades. There is a fall in the 20 year group followed by a high level after the age of 30 years. It is noticeable that whereas males predominate under the age of $\mathbf{2 0}$ females are greatly in excess after 30 years. Rose (1954), in his analysis of a rather larger group of mixed cases, also drew attention to the preponderance of females in the older group, as has Payne (1933, 1940). Jones (1953) records a slight excess of males over females in a group of 17 children.

The investigation has been undertaken on the basis of history, physical examination of the swellings and of Stenson's duct, examination of saliva obtained from the duct, and sialography. All these contribute to the diagnosis but for the moment the results of sialography only will be considered. For this a long No. $22 \mathrm{G}$ needle with solder attached 3-5 $\mathrm{mm}$. from the distal end was used (Fig. 1). The solder can be wedged up against the duct orifice to prevent reflux. A watery solution of neohydriol is injected: Most normal duct systems will accommodate $\frac{1}{2}-1 \mathrm{ml}$. without rupture of the acini but when the main ducts are dilated 2 or $3 \mathrm{ml}$. may be required to obtain adequate filling. Sialograms fall into four main patterns: 1, Normal appearance; 2, dilatation of the terminal ducts or acini; 3, dilatation of the main and/or main branch ducts; 4 , filling defects in main or branch ducts due to calculus with dilatation of ducts distal to obstruction. The presence of tumours may be indicated by displacement of the branch ducts, and parenchymatous swellings by separation of the ducts from one another.

Those cases falling into groups 2 and 3 , according to age and sex, are analyzed in Table II.

\section{TABLE II}

ANALYSIS OF GROUPS 2 AND 3

\begin{tabular}{|c|c|c|c|c|c|c|c|}
\hline & $\begin{array}{l}\text { Age in } \\
0-9\end{array}$ & $\begin{array}{c}\text { Years } \\
10-19\end{array}$ & $20-29$ & $30-39$ & $40-49$ & $50-59$ & $60+$ \\
\hline & \multicolumn{7}{|c|}{ Terminal Dilatation } \\
\hline Male & 8 & 8 & 1 & 0 & 1 & 0 & 0 \\
\hline Female & 4 & 3 & 1 & 3 & j & 2 & 1 \\
\hline Total & \multicolumn{7}{|c|}{ Main Duct Dilatation } \\
\hline Male & 0 & 0 & 2 & $\mathbf{0}$ & 0 & 1 & 0 \\
\hline Female & 0 & 0 & 2 & 2 & 3 & 9 & 6 \\
\hline Total & 0 & 0 & 2 & 2 & 3 & 9 & 6 \\
\hline
\end{tabular}

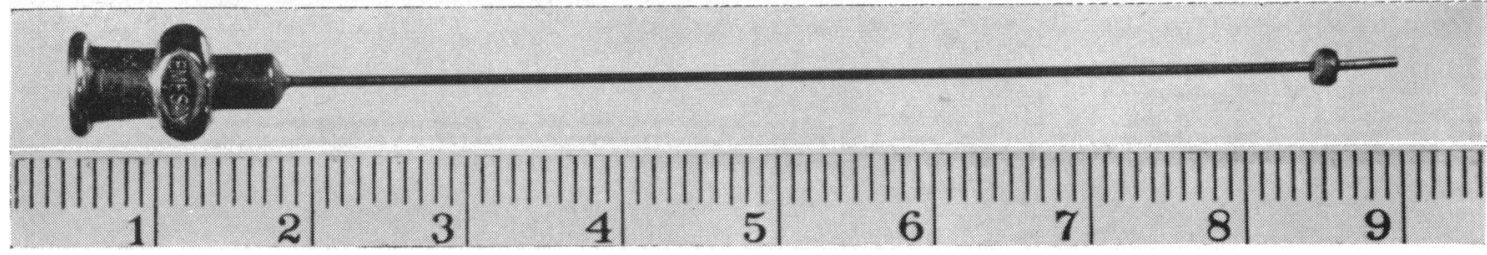

FIG. 1. Needle employed for introduction of Neohydriol into Stenson's duct (scale in cm.). 
Terminal duct dilatation therefore occurs most frequently in the first two decades, with males predominating over females in the proportion of two to one. Main duct dilatation occurs very much more commonly in females and is rare under $\mathbf{4 0}$ years of age. Those with normal sialograms on the whole reflect the findings in the group with terminal duct dilatation, occurring most commonly before the age of 20 with a $4: 1$ excess of males over females. Those in whom sialography was not carried out clearly include cases from both the youthful group and the older female cases (Table III).

\section{TABLE III}

SIALOGRAM FINDINGS RELATED TO AGE AND SEX

\begin{tabular}{|c|c|c|c|c|c|c|c|}
\hline & $\begin{array}{l}\text { Age in } \\
0-9\end{array}$ & $\begin{array}{c}\text { Years } \\
10-19\end{array}$ & $20-29$ & $30-39$ & $40-49$ & $50-59$ & $60-69$ \\
\hline & \multicolumn{7}{|c|}{ Normal Sialograms } \\
\hline Male & 6 & 2 & 1 & 1 & 1 & $\mathbf{0}$ & 0 \\
\hline Female & 1 & 1 & 3 & 4 & 1 & 1 & 0 \\
\hline Total & 7 & 3 & 4 & 5 & 2 & 1 & 0 \\
\hline \multicolumn{8}{|c|}{ Sialograms Not Done } \\
\hline Male & 4 & 0 & 0 & 0 & 0 & 0 & 0 \\
\hline Female & 3 & 0 & 0 & 1 & 3 & 2 & 1 \\
\hline Total & 7 & 0 & 0 & 1 & 3 & $\overline{2}$ & 1 \\
\hline
\end{tabular}

There remain 14 patients with filling defects and localized distensions; these were all over 20 , and included seven males and seven females. All had calculus formation and will be more fully discussed later.

For the purpose of this paper cases have been classified on clinical grounds under five main headings: 1, Infective; 2, Sjögren's syndrome; 3 , calculus formation; 4, allergic; and 5, doubtful origin. It should be pointed out that infection of the duct system is not limited to group 1. Many cases of parotid swelling in Sjögren's syndrome are infected, and infection, possibly secondary, is present in many cases of calculus obstruction and may also occur in those with allergy.

\section{INFECTIVE GROUP}

These patients have periodic attacks of swelling of the parotid gland, usually for several days or weeks at a time with intervals of freedom. The gland is often tender, the duct orifice reddened, and purulent debris can sometimes be expressed from it. Organisms, including Strep. viridans, pneumococcus, Staph. aureus, haemolytic streptococci, and Staph. albus, have all been cultivated from the parotid secretions, but it is difficult to avoid contamination with mouth organisms, and cultures from saliva which do not contain pus should be accepted with caution. Patients frequently complain of an unpleasant taste in the mouth. In cases of doubt resolution after treatment with tetracycline or penicillin may provide confirmatory evidence of infection.
The group contains 39 patients: 21 were under the age of 20 and of these 15 were males. All those investigated by sialography had terminal duct dilatation (15) or normal ducts (4). Two also had irregular dilatation of one main duct. There were 16 cases over 30: 15 were females and one male. Ten had dilated main ducts, three terminal dilatation, and one a normal sialogram. In two cases sialograms were not obtained. Of those with dilatations of the terminal ducts, 12 had bilateral swellings, seven unilateral. Two of the latter showed terminal dilatation on the unaffected side as well as on the affected.

CASE 1 This boy, aged 10 years, is the only diabetic in the series. He has had recurrent swellings of the parotid glands for six years. The left side has been repeatedly affected but the right side on one occasion only. Pressure over the distended glands on the left side caused exudation of pus from Stenson's duct. Strep. pneumoniae was obtained on culture. Sialography showed that the terminal ducts were dilated on both sides (Fig. 2). A biopsy obtained from the left side (Fig. 3) shows dilated acini with fine interstitial fibrosis and patchy infiltration by chronic inflammatory cells. Polymorphs are present in some of the smaller ducts. The appearance is typical of a recurrent parotitis in an active phase.

The patients with main duct obstruction can be divided into those in whom obstruction was at the orifice of the duct (seven cases) and those in whom the obstruction occurred at some point in the course of the main duct distal from the orifice (six cases). Four in each group had bilateral swellings. Two patients with unilateral swellings showed obstruction at some distance from the duct orifice $w$ ith an appearance very suggestive of calculus formation (filling defects in duct) but no confirmatory evidence was obtained. Terminal duct dilatation was present in two cases with dilatation of the main duct. In two

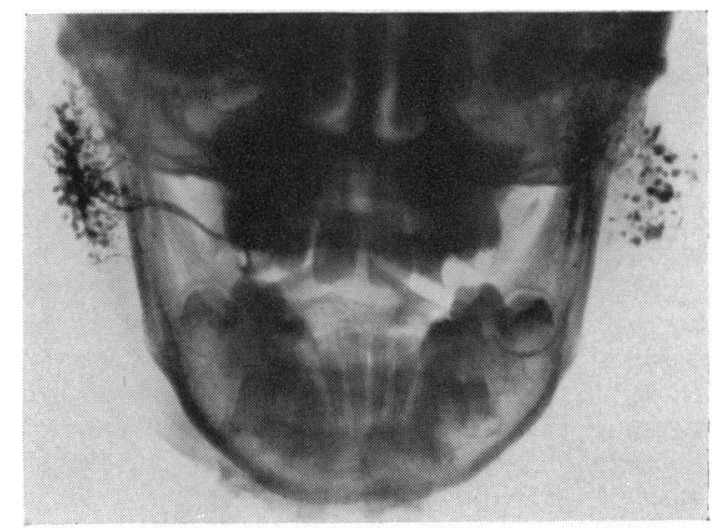

FIG. 2. Case 1 showing bilateral terminal dilatation of ducts. Recurrent infection. 
cases the swelling was first noticed shortly after extraction of teeth.

CASE 2 A woman aged 65 had had recurrent swellings of both parotid glands since she was 50 years of age. The swelling persisted for from two to seven days. Turbid purulent fluid was expressed from the duct and on culture Strep. viridans was grown. Both main ducts were dilated and biopsy of the glands showed a normal appearance apart from some atrophy and fat replacement (Fig. 4).

\section{SJÖGREN'S SYNDROME}

These patients presented with the characteristic history of dry mouth, dry, painful eyes, and in the majority widespread rheumatoid arthritis. Nineteen cases were investigated but six of these gave no history of parotid swelling at any time and are not included in this series. Some of them, however, had sialograms carried out and two showed scattered dilatations of terminal acini and one, dilated branch ducts. Of the remaining 13 patients, four were in their late 30s and nine were over 40 . All were women except for one man of 68 years. The swellings were bilateral in 12 and fluctuated in size but rarely sub- sided completely. Sialograms were carried out in eight patients, two were normal, four had dilatations of the terminal ducts, and in two the main and branch ducts were dilated. Poor filling of branch ducts due to atrophic changes is characteristic of this condition. Two patients could not be investigated radiologically because thick, cheesy debris was constantly present in Stenson's duct from which only small quantities could be expressed. These two patients had persistent and extensive swelling of the parotid glands at the time of investigation. One patient (with main duct dilatation) had had an acute parotitis due to Staph. aureus, and surgical drainage was necessary on two occasions. The histology of the glands in this condition has been described by Cardell and Gurling (1954).

CASE 3 For four years this patient, a woman aged 54, had complained of multiple joint pains causing moderate disability. Three years previously the left parotid gland became swollen and red. Afterwards she noticed that her mouth became very dry. The swelling fluctuated but never entirely subsided. At a later date the right parotid gland became slightly swollen and marked keratoconjunctivitis sicca was present. 


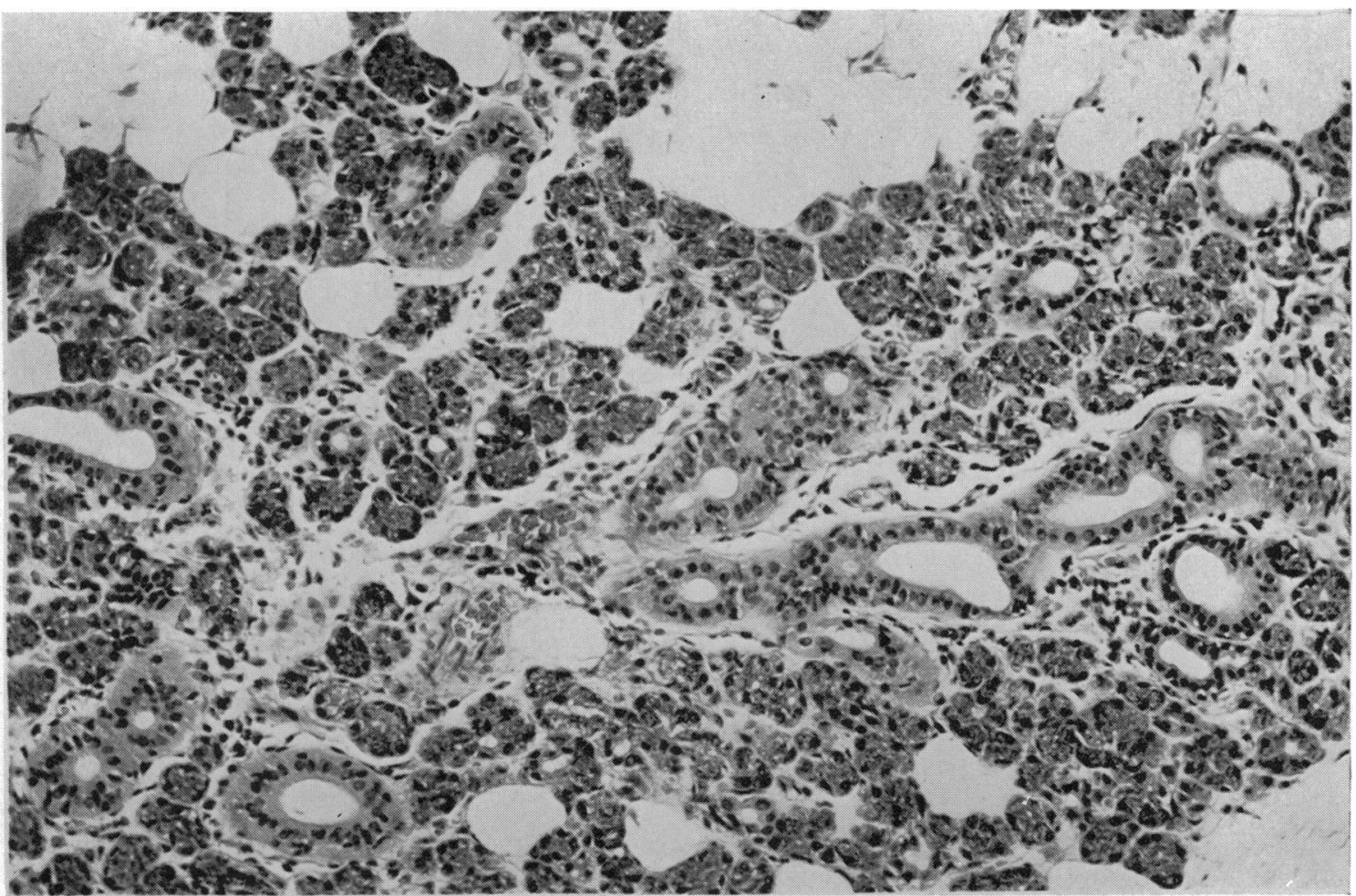

FIG. 4. Case 2. Biopsy (haematoxylin and eosin $\times 200$ ) showing minimal glandular atrophy and fat replacement.

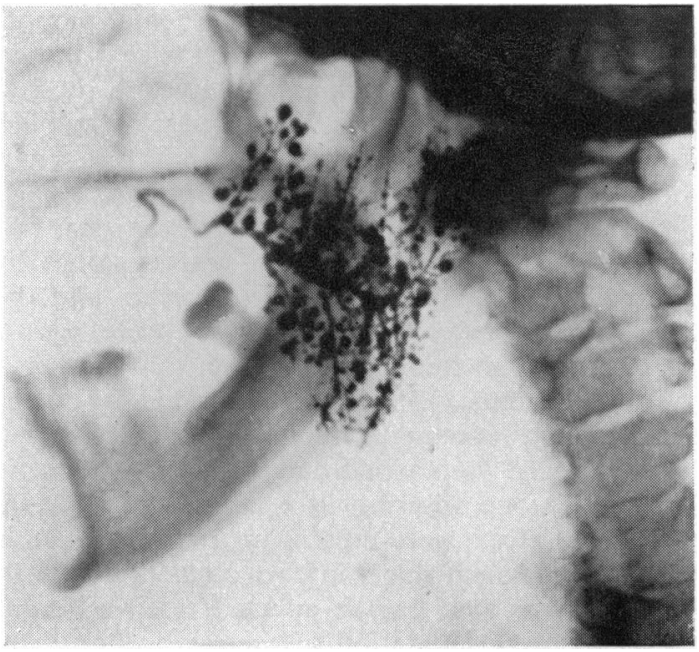

FIG. 5. A sialogram of Case 3 showing terminal dilatation.
A sialogram showed extensive dilatation of the terminal ducts and some irregular dilatation of the main duct (Fig. 5). Section on the left side confirmed the dilatation with evidence of chronic inflammation and residual glandular tissue undergoing hyalinization (Fig. 6).

CASE 4 A woman aged 36 first had symptoms of rheumatoid arthritis at the age of 23 . These cleared up but returned after pregnancy at 29 and her condition has steadily deteriorated since then. At 28 she noticed swelling of the parotid glands on eating (for the past two years the swelling has been persistent). Treatment with corticotrophin caused the swelling to subside temporarily but no increase in secretion. For two years her mouth has been persistently dry and she has had a pricking sensation in the eyes. A sialogram showed dilatation of the terminal ducts. The branches of Stenson's duct were characteristically scanty due to atrophy of glandular tissue (Fig. 7). Section showed parenchymal atrophy and replacement by lymphoid tissue, typical of the changes described by Cardell and Gurling.

\section{CALCULUS FORMATION}

These cases presented with a history of pain and swelling on the side of the calculus formation. There 


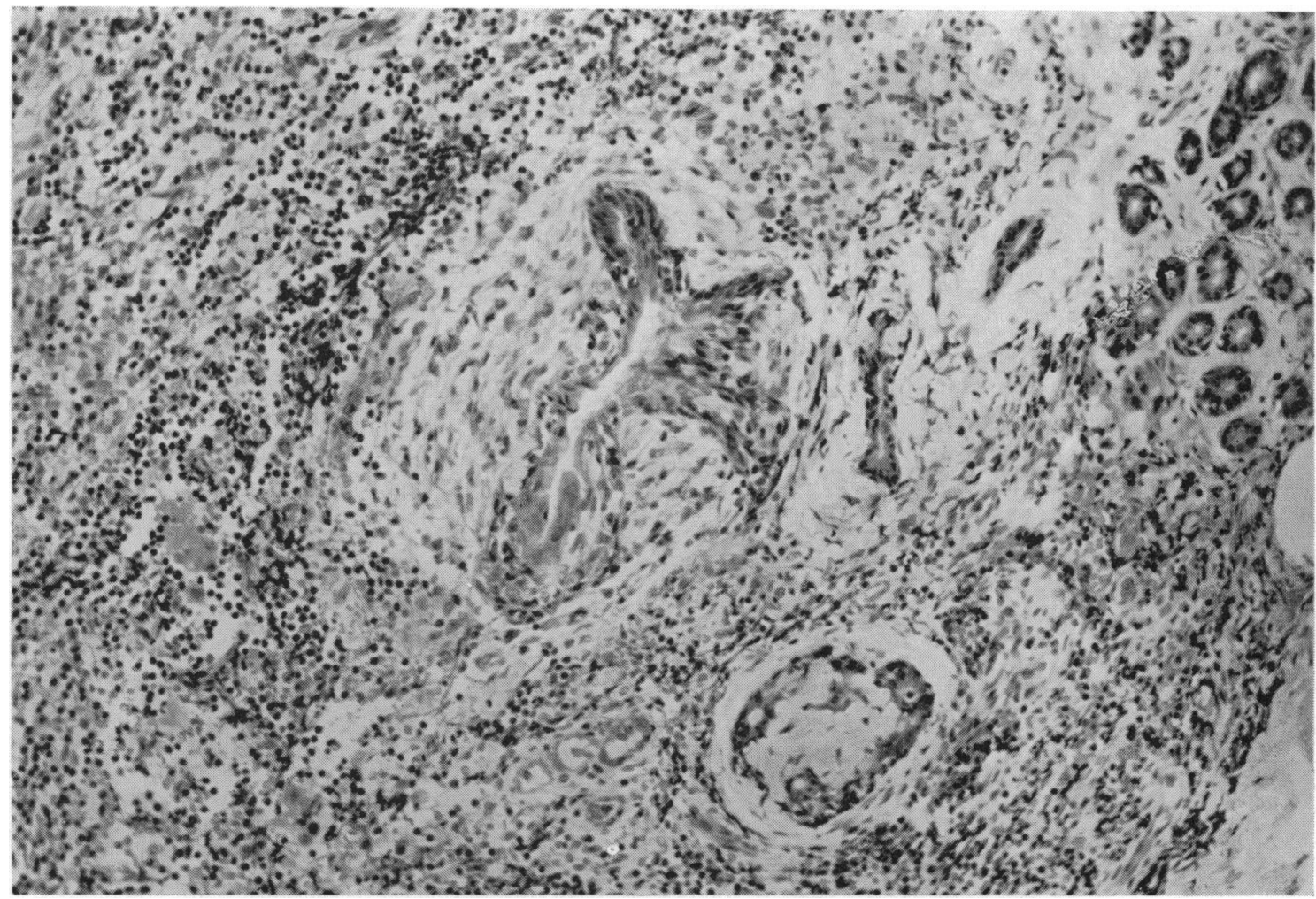

FIG. 6. Case 3. Biopsy of parotid gland (haematoxylin and eosin $\times 200$ ) showing glandular atrophy with evidence of chronic inflammation.

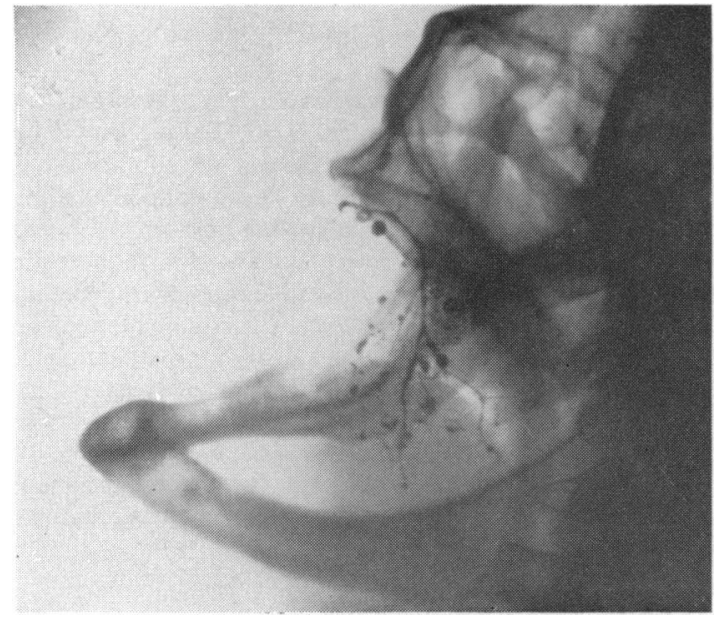

FIG. 7. Sialogram of Case 4, showing scanty branch ducts with terminal dilatation. was evidence of infection in seven out of 14 cases but it was certainly not invariably present. For example, a man aged 43 noticed an acute, painful swelling of the left parotid gland while eating on two occasions, and on the second of these he pressed firmly over the swelling, which caused a sharp pain deep in the gland, followed by expulsion of a small phosphate calculus the size of a grape pip and a gush of pent-up secretion. Since this patient was seen, two other patients have been able to express stones by pressure in this way, one after nine years and the other after four years. Stones or grit were passed spontaneously in four other cases and in another a calculus was removed from the main duct at operation. Swellings were unilateral in all cases except two.

Sialography was carried out in 13 cases. In only two was a stone observed in a straight radiograph, but filling defects were present in the main duct in five and in branch ducts in two other patients. In two the main duct on the affected side was completely blocked. Dilatation of the main duct distal to the obstruction was demonstrated in eight cases, and localized dilatations of branch ducts in six (in 
these both main duct and localized dilatations were present). Twelve patients were 37 years of age or more and the sex distribution was equal.

CASE 5 A man aged 37 complained of swelling of the left side of the face intermittently for one year. It was often made worse by eating and might persist for two weeks at a time. Pressure over the gland caused turbid fluid to exude from Stenson's duct. A calculus, approximately $1 \mathrm{~cm}$. in length, could be felt at the edge of the masseter. A sialogram showed a convex filling defect in the main duct from which a radiotranslucent stone was subsequently removed (Fig. 8).

CASE 6 A man aged 59 had had recurrent swelling of the right parotid gland at irregular intervals during six or seven years. Small pieces of grit have been expelled from Stenson's duct from time to time. A sialogram showed a filling defect at the point of subdivision of the main duct with localized swelling of the branch duct (Fig. 9).

\section{CASES WITH EVIDENCE OF ALLERGIC AETIOLOGY}

These include 16 cases, 11 females and five males. Six patients, all women between the ages of 37 and 70 with bilateral swellings, had dilated main ducts, in one case limited to one side. The swellings appeared very frequently, sometimes during every meal. These cases have been described in detail elsewhere (Pearson, 1951). All gave a history of expelling mucus plugs followed by clear saliva from the duct orifices by pressure over the dilated gland, and microscopical examination showed that the plugs contained numerous eosinophils and in one polymorphs also. Four had asthma and two rhinorrhoea. All except one had a high eosinophil count in the

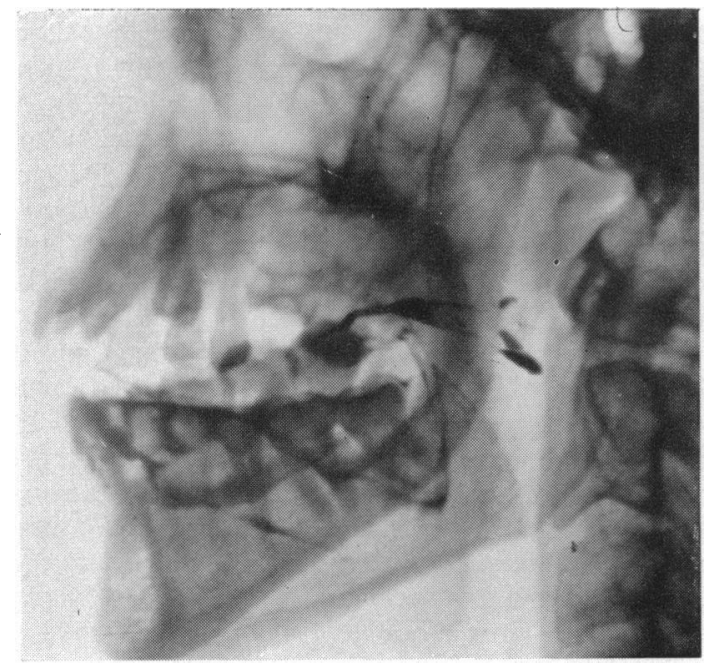

FIG. 8. Case 5. Sialogram showing radiotranslucent stone in Stenson's duct. blood. In some cases the eating of specific foods was considered by the patient to cause swelling, but this could not always be confirmed by observation. There is no reasonable doubt that eosinophilic mucus plugs which blocked the orifices of Stenson's ducts accounted for the swellings in these cases.

There were 10 other patients in whom allergy was thought to play some part in the aetiology. Three of these had terminal duct dilatations and five normal sialograms, including one of a patient with a history of many years' recurrent swellings. The ages of this group varied from 4 to 61 but only three were over 20. In none of these patients was purulent material ever seen emerging from Stenson's duct. The duration of episodes of swelling was brief in most cases. Four patients had asthma, two had had migraine at the same time as swellings were present, and one patient developed parotid swellings as part of a gold sensitivity reaction.

CASE 7 A girl aged 17 suffered from periodic swelling of both parotid glands for one day at a time. These swellings often followed the eating of egg in cake or pudding. Eggs have always caused vomiting, and eating a boiled egg was followed the next day by migraine, vomiting, and bilateral parotid swellings. A sialogram (Fig. 10) showed scattered dilatation of terminal ducts. She had no more swellings after the age of 19 . The patient continues to avoid eggs.

\section{SWELLINGS OF DOUBTFUL ORIGIN}

This group includes 22 cases $(11$ males and 11 females). Twelve had bilateral swellings. Ten were under the age of 10 , and six were over 30 years of

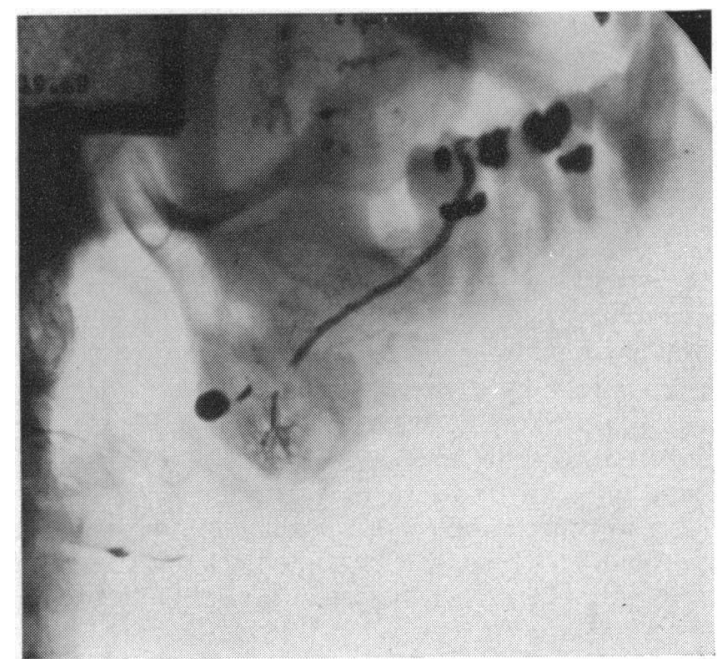

FIG. 9. Case 6. Sialogram with filling defect due to calculus. 


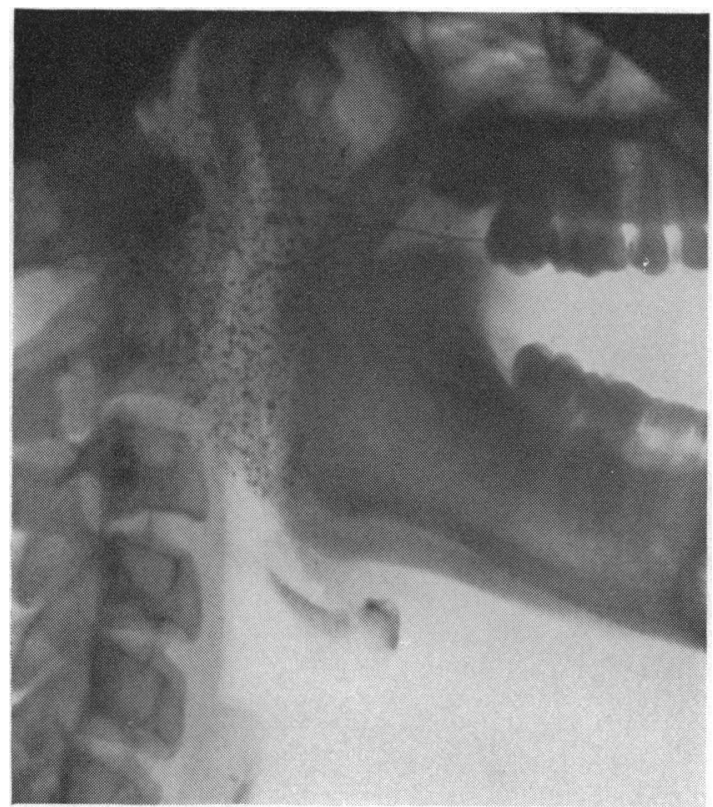

FIG. 10. Case 7 showing terminal duct dilatation in recurrent swelling of allergic origin.

age. One woman of 66 had a dilated main duct, five had terminal dilatations, and eight had normal sialograms. Three were asthmatic. Two were siblings, and one other, a woman of 26 , was the sister of a boy in the infected group. In some cases the swelling was almost certainly confined to the glandular or interstitial tissues and unassociated with duct obstruction.

\section{TRAUMA TO DUCT ORIFICE}

One patient, a woman of 58 , was observed to have a lesion of the duct papilla on one side, probably caused by trauma from ill-fitting dentures.

\section{DISCUSSION}

Recurrent swellings of the parotid glands are not uncommon and present a difficult and complicated problem in pathogenesis. The tendency to develop bilateral swellings, often simultaneously, the changing sex ratio with increasing age accompanied by change in the sialographic appearances from dilated terminal ducts or acini in youth to dilatation of the main ducts in older people, all offer a tempting bait for speculation. There has been no lack of suggested aetiological factors, including infection (Payne, Rose, Jones), allergy (Pearson, 1935, 1936; Serafini, 1951 ; Waldbott and Shea, 1947; Findeisen, 1956; Riley, 1956), dental trauma (Rose, 1954), dehydration, diabetes (Lyon, 1943), improper mastication (Payne,
1940), heredity (Smith, 1953), auto-immune disease (Mosbech, Kristensen, 1960), and sialorrhoea (Reimann and Lindquist, 1952).

Parotid calculi are recognized but generally considered rare. In the present series of cases parotid calculi were identified in 14 patients. This was the only group of middle-aged or elderly patients in whom males were as numerous as females, and the only group in which unilateral swellings were more often seen than bilateral. The diagnosis is not always easy because the calculus may be small or radiotranslucent. Sialography may reveal a filling defect in the main or branch duct, with dilatation beyond it, and is an essential feature of the investigation of suspected cases. Infection may be present, but is probably secondary to obstruction in most cases.

In Sjögren's syndrome the dry mouth and poor salivary flow may be considered to account at least partly for the recurrent swellings found in this condition by predisposing to ascending infection. The reduction in size of the glands after treatment with corticotrophin suggests that there is also inflammatory swelling of the interstitial tissues (Gurling, Pearson, and Pond, 1954). The patients are almost exclusively female, and in the present series this was the only group of elderly women in whom dilatation of the terminal ducts was common. Main duct dilatation may also occur. The most characteristic feature of the sialogram is the small number of branch ducts. This is accounted for by atrophy of the gland and its replacement with fibro-adipose tissue (Cardell and Gurling, 1954).

Allergy can also reasonably be accepted as of some importance as an aetiological factor. The older patients are exclusively female and the swellings, which are chiefly of the main and branch ducts, are caused by eosinophilic plugs obstructing the orifices of Stenson's ducts from which they can readily be ejected by pressure. In these cases dilatation of the terminal ducts has not been seen. In the younger patients, however, males predominate and the sialographic appearances are either normal or with terminal duct dilatation. No patient under 30 was found to have a dilated main duct.

A similar relationship between age and sex and in the sialographic pattern is seen in the infected cases, and expression of mucous plugs containing polymorphs is sometimes encountered in the middle-aged women who mainly form this group. The organisms isolated from the purulent secretions in these patients are most commonly Strep. viridans and less frequently pneumococci and Staph. aureus (Payne, 1933, 1900). These findings have been confirmed in the present series.

It is difficult to understand why the pattern of duct obstruction should differ in patients of different ages, 
even when the aetiological factors are not identical, e.g., infection, allergy, and cases without obvious aetiology. There is general agreement that duct infection is almost invariably an ascending one. It seems that in young patients the infection may ascend rapidly into the branch ducts, where swelling of the mucosal lining of the intercalary ducts or of the interstitial tissue itself obstructs the lumen. Biopsy specimens from such cases confirm this view, revealing inflammatory change in the interstitial tissues with purulent material in small ducts. In these cases there is a definite tendency for improvement during adolescence when recurrent swellings disappear. Spontaneous remissions also take place in young patients with an allergic basis and those without obvious aetiological factors. In adults the main reaction to both ascending infection and allergic processes appears to be in the main duct, which responds by secretion of mucus and shedding of the lining cells of the duct to form masses which obstruct the main duct orifice causing it and its main branches to dilate. In other cases constrictions seen in the course of the main duct may indicate fibrous stricture. Biopsy of the gland in these cases shows little change in the acini and interstitial tissues. The tendency to form tenacious mucus is of course more apparent in the bronchial tract in older patients, especially those with bronchitis. It seems possible that the mucus-secreting glands which are found in Stenson's duct are also more active in this age group and pour out their secretions as a result of infective, allergic, or other stimuli.

Hereditary or congenital abnormalities of the ducts have been suggested as a possible basis for recurrent swellings. In the present series of cases there are two pairs of siblings, the first ${ }^{1}$ a boy aged 12 with infective sialodochitis and terminal duct dilatation with early involvement of the main ducts, and his sister aged 26 years. She had had recurrent swellings as a child but at the time of investigation had been free of symptoms for some years but sialography still revealed bilateral terminal dilatation of the ducts. ${ }^{1}$ The second pair were brothers aged $4 \frac{1}{2}$ and 1 year 9 months. Both were asthmatics but the aetiology of the swellings was considered uncertain and sialograms were not carried out. Two other patients who gave a history of unilateral swelling associated with infection had terminal duct dilatations on both sides. Rose quotes 10 cases in children between the age of 3 and 15 years who had advanced changes in the duct system in spite of a short and comparatively mild history, which he regards as evidence of pre-existing acinar dilatations. Smith (1953) records recurrent parotid swellings with radio-

'Previously reported (Pearson, 1935). logical evidence of duct dilatation in three generations of a family.

Recurrent attacks of sialorrhoea may account for some of the transient bilateral swellings without evidence of infection or allergy (Reimann and Lindquist, 1952). Improper mastication with a consequently inadequate salivary flow (Payne, 1940) may well predispose to ascending infection, but this is difficult to determine. It may help to explain the onset of infection after dental extractions. Stenosis of the duct or duct papilla due to trauma from a faulty bite has been regarded as a relatively common cause of parotid swelling (Rose). Although the duct orifices are sometimes small and a cannula may be difficult to pass, especially when the orifice is on a mobile papilla, we have only encountered one case where there was evidence of trauma from a newly acquired set of dentures. The swelling was unilateral.

We have found no evidence that diabetes mellitus is a predisposing factor of importance. In spite of a careful search in the Diabetic Department at King's College Hospital, only one case of pneumococcal sialodochitis, in a diabetic boy aged 11, has been referred.

It is clear that there is a group of patients in whom the aetiological factor is obscure, and even when infection is present the underlying predisposing abnormality often remains unrecognized.

I should like to express my thanks to Dr. B. S. Cardell for help and advices.

\section{REFERENCES}

Cardell, B. S., and Gurling, K. J. (1954). Observations on the pathology of Sjögren's syndrome. J. Path. Bact., 68, 137-146.

Findeisen, D. G. R. (1956). Allergy to dentures: A report of two cases presenting asthma and parotitis. Int. Arch. Allergy, 9, 281-284.

Gurling, K. J., Pearson, R. S. B., and Pond, M. H. (1954). Sjögren's syndrome treated with A.C.T.H. Brit. J. Opthal., 38, 619-652.

Jones, H. Everley. (1953). Recurrent parotitis in children. Arch. Dis. Childh., 28, 182-186.

Lyon, E. (1943). Swelling of the parotid gland and diabetes mellitus. Int. J. Gastroent., 68, 139-147.

Mosbech, S., and Kristensen, H. P. O. (1960). Chronic Sialoadenitis caused by autoimmunisation. Acta med. scand., 168, 147-150.

Payne, R. T. (1933). Recurrent pyogenic parotitis. Lancet, 1, 348-353.

(1940). Pneumococcal parotitis. Brit. med. J., 1, 287-292.

Pearson, R. S. B. (1935). Recurrent swelling of the parotid glands. Arch. Dis. Childh., 10, 363-376.

(1936). Two cases of recurrent swelling of the parotids. Guy's Hosp. Rep., 86, 333-342.

- (1951). Parotid swelling due to allergic obstruction of the main duct. Proceedings of First International Congress for Allergy, Basel, pp. 868-873.

Riley, H. D. (1956). Recurrent parotid swelling. Sth. med. J. (Bgham, Ala.), 49, 523-528.

Rose, S. S. (1954). A clinical and radiological survey of 192 cases of recurrent swellings of the salivary glands. Ann. roy. Coll. Surg., $15,374-401$.

Reimann, H. A., and Lindquist, J. N. (1952). Periodic sialorrhea. J. Amer. med. Ass., 149, 1465-1467.

Serafini, U. (1951). Prime osservazioni su alcuni casi di tumefazione acuta ricorrente della parotide di probabile origine allergica. Minerva med. (Torino), 17, 271-275.

Smith, M. (1953). Familial incidence of sialectatis. Brit. med. J., 2, 1359.

Waldbott, G. L., and Shea, J. J. (1947). Allergic parotitis. J. Allergy, 18, 51-54. 